\title{
SUCROQUÍMICA: SÍNTESE E POTENCIALIDADES DE APLICAÇÕES DE ALGUNS DERIVADOS QUÍMICOS DE SACAROSE
}

\author{
Maurício Boscolo \\ Departamento de Química e Ciências Ambientais, Instituto de Biociências, Letras e Ciências Exatas de São José do Rio Preto, \\ Universidade Estadual Paulista, 15054-000 São José do Rio Preto - SP \\ Recebido em 13/8/02; aceito em 19/5/03

\begin{abstract}
SUCROCHEMISTRY: SYNTHESIS AND POTENTIALITIES FOR APPLICATIONS OF SOME SUCROSE CHEMICAL DERIVATIVES. The interest on the use of sucrose as raw material increased in the last years. In this work, the synthesis and applications of sucrose derivatives as esters, ethers, and other products are discussed in a concise manner aiming to presenting the sucrochemistry as a promising field in organic chemistry from a rather accessible, low-priced, ecological, and renewable source.
\end{abstract}

Keywords: sucrose; sucrochemistry; sugar cane.

\section{INTRODUÇÃO}

No Brasil, a cana-de-açúcar é sem dúvida uma das culturas agrícolas mais importantes. A safra 2000/2001 rendeu 16 milhões de toneladas em açúcar ${ }^{1}$ e, embora a produção de açúcar necessite de vultosos investimentos em plantas industriais para atingir o volume de produção compatível com a escala de mercado, o preço do produto refinado é relativamente baixo em função da ampla oferta existente e do pouco valor agregado, ao contrário dos seus derivados químicos.

Sendo uma matéria-prima de fonte renovável e de baixo custo, a sacarose vem despertando um crescente interesse como reagente na síntese de surfactantes não-iônicos ${ }^{2}$, polímeros ${ }^{3}$, $\operatorname{adoçantes~}^{4}$, emulsificantes ${ }^{5,6}$, entre outros. $\mathrm{O}$ segmento da química focado na síntese de derivados de açúcar $^{7}$ passou a ser denominado como Sucroquímica.

Um indicador do potencial tecnológico da sacarose como substrato é o elevado número de patentes de aplicações somente para os ésteres de sacarose, contrastando com os poucos artigos científicos publicados sobre o tema ${ }^{6}$. Entretanto, o uso da sacarose refinada se restringe basicamente a finalidades alimentícias. Estimativas feitas na década de 80 indicavam que cerca de $0,1 \%$ da sacarose refinada produzida mundialmente era empregada como insumo químico na indústria de transformação ${ }^{8}$. No final da última década foi divulgado que menos de $2 \%$ da produção de açúcar dos EUA foram destinados a usos não alimentícios ${ }^{9}$. As sínteses e aplicações de alguns sucroderivados serão discutidas ao longo deste artigo.

\section{O açúcar de cana como um reagente}

A sacarose ou 1-O-( $\beta$-D-Frutofuranosil)- $\alpha$-D-glicopiranose é composta por frutose e glicose unidas por uma ligação glicosídica (Figura 1) sendo classificada como um poliol ${ }^{7}$, com oito grupos hidroxilas reagentes, três primários $(6,1$ ' e 6') e cinco secundários (2, 3, 4, 3'e 4').

Assim como os álcoois, a partir da sacarose pode-se obter ésteres, éteres, uretanas, além da possibilidade dos grupos hidroxilas serem substituídos por hidrogênio, haletos, tióis, tiocianatos, tioacetatos,

e-mail: boscolo@qca.ibilce.unesp.br

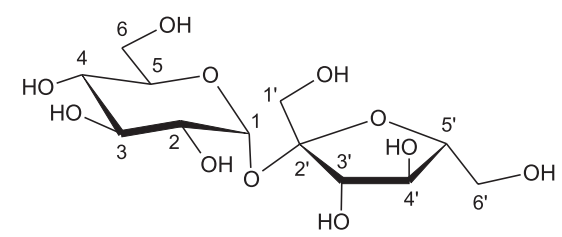

Figura 1. Estrutura da sacarose

azidas e outros grupos monovalentes ${ }^{8}$, implicando em modificações nas suas propriedades químicas, e podendo resultar em compostos de interesse tecnológico.

A dificuldade em se controlar o grau e a seletividade das reações envolvendo as hidroxilas da sacarose tem sido um problema na sucroquímica $^{10}$. As hidroxilas primárias são as mais reativas apenas nas reações em que fatores estéricos sejam importantes ${ }^{4}$, sendo a hidroxila da posição 2 a mais ácida dentre todas e, conseqüentemente, a mais reativa ${ }^{11}$. Isto ocorre tanto em solventes orgânicos, devido às fortes ligações de hidrogênio envolvendo O-2 e OH-1' ou OH-3', como em meio aquoso, com a incorporação de uma molécula de água $^{10}$ (Figura 2).

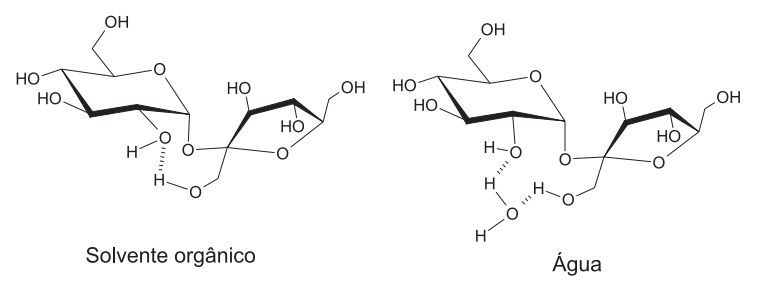

Figura 2. Ligações de hidrogênio em meio orgânico e aquoso envolvendo a hidroxila $\mathrm{OH}-2$

Em condições aniônicas não-seletivas, ou seja, com a formação do íon sucrato, a reatividade das hidroxilas obedece à seguinte ordem ${ }^{11}$ : O-2 >> O-1'> O-3 '> O-6 > O-6'. Entretanto, na presença de $\mathrm{Mn}(\mathrm{II})$ ou $\mathrm{Co}(\mathrm{II})$ a ordem de reatividade das hidroxilas da sacarose é alterada (O-3' >> O-2 > O-1' > outras) em função de alterações da nucleofilicidade das hidroxilas da sacarose coordenadas ${ }^{4}$. 
A complexidade de produtos que podem ser obtidos em uma micela reacional, tendo a sacarose como reagente é considerável. Teoricamente, com o grau de substituição variando de um a oito e todas as possibilidades de combinações dos regioisômeros, o número de compostos que pode ser obtido por substituições na sacarose a partir de um único reagente pode chegar a 255 , de acordo com a Equação 1,

$i=\sum_{m=1}^{8} \frac{8 !}{m !(8-m) !}$

onde $i$ é o número total de compostos possíveis e $m$ o grau de substituições. Porém, assim como em um processo competitivo, fatores termodinâmicos e de solvatação contribuem para que ocorram migrações intra e intermoleculares dos grupos substituintes das hidroxilas secundárias para as primárias ${ }^{10}$, possibilitando uma redução no número de regioisômeros produzidos.

\section{Ésteres de sacarose}

Os ésteres de sacarose ou sucroésteres obtidos a partir de ácidos graxos são compostos anfifílicos ${ }^{12}$, atóxicos, compatíveis com a pele e digestíveis ${ }^{13}$ quando o grau de esterificação for $\leq 3$. O balanço entre a hidrofilicidade e a lipofilicidade dos sucroésteres (HLB"hydrophilic/lipophilic balance") não é significativamente alterado por variações na temperatura, mas pode ser regulado pelo grau de substituições e pelo tamanho e número de insaturações das cadeias alquílicas ${ }^{2}$. Desta forma, é possível conseguir uma grande variação nas características surfactantes dos sucroésteres. Dado que a escala de HLB $^{14}$ varia de 0 a 20, sucroésteres com alto valor de HLB solubilizam óleo em água, enquanto os sucroésteres com baixos valores de HLB solubilizam água em óleo ${ }^{12}$. A título de exemplo, o monolaurato de sacarose (Figura 3a) apresenta HLB igual a 16 e o HLB do dilaurato de sacarose (Figura $3 b$ ) é igual a 5.
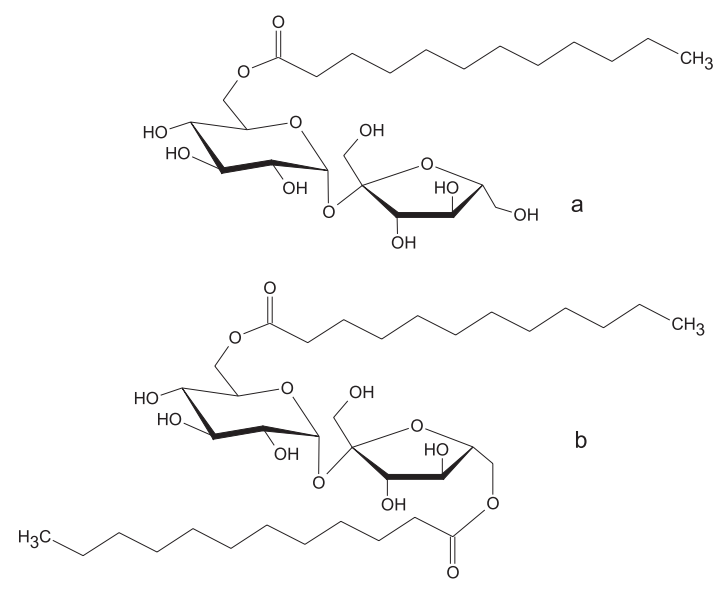

Figura 3. Exemplos de ésteres de sacarose: (a) 6-O-laurato de sacarose, (b) 6,6'-O-dilaurato de sacarose

Em função da fragilidade da ligação glicosídica em meio aquoso ácido, os sucroésteres não podem ser produzidos pela esterificação direta dos ácidos carboxílicos com a sacarose por catálise ácida, uma vez que o meio ácido irá promover a inversão da sacarose. Assim, os sucroésteres são normalmente produzidos a partir de cloretos de ácidos, anidridos e principalmente por transesterificação.

Ésteres metílicos de ácidos graxos dos óleos vegetais e os glicerídeos de origem animal podem ser transesterificados com a sacarose em processos livres de solventes ${ }^{15}$. Nestes casos, como os reagentes são pouco voláteis, as reações devem ser processadas sob vácuo para a remoção do metanol e do glicerol produzidos, respectivamente, favorecendo o deslocamento do equilíbrio da reação para os produtos. O uso de tal artifício torna-se desnecessário quando os ésteres de partida são vinílicos ou isopropenílicos ${ }^{16}$ (Esquema 1), pois destes, ao invés de metanol, resultam compostos não competitivos nas reações de transesterificação, como o acetaldeído e a acetona.
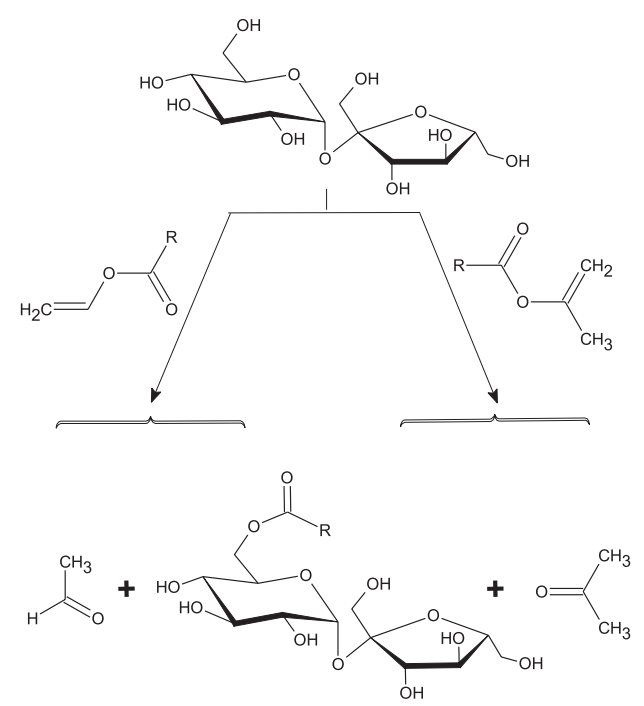

Esquema 1. Transesterificação da sacarose com ésteres isopropenílicos e vinílicos. Exemplo de um regioisômero de monoéster de sacarose. (Outros isômeros são possíveis)

A reação da sacarose com cloretos de ácidos orgânicos ${ }^{10}$ para a obtenção de ésteres pode ser conduzida em meio alcalino para neutralizar o $\mathrm{HCl}$ liberado na reação, evitando-se assim a inversão da sacarose (Esquema 2).
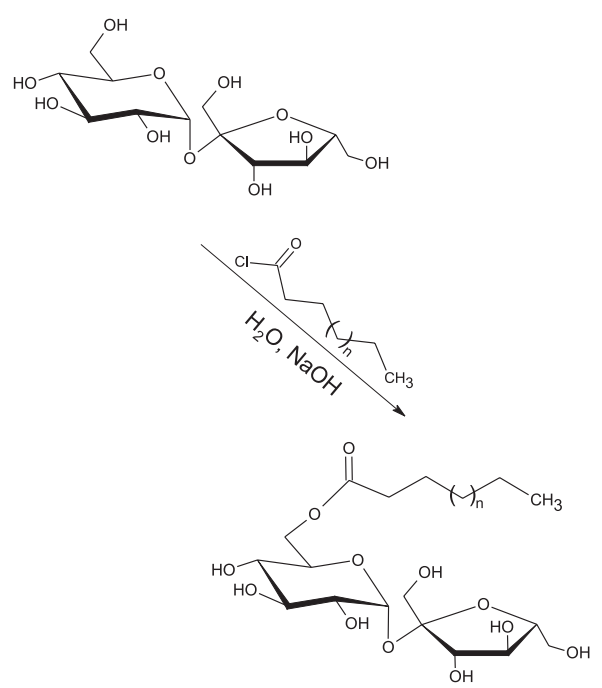

Esquema 2. Síntese de um monoéster de sacarose a partir de cloreto de ácido graxo em meio alcalino. (Outros isômeros são possíveis)

Monoésteres de sacarose com cadeias alquílicas entre oito e dezesseis carbonos são excelentes surfactantes não-iônicos, enquanto os sucroésteres com cadeias alquílicas maiores que dezoito carbonos apresentam pouca ou nenhuma solubilidade em água, o que inviabiliza suas aplicações como tensoativos ${ }^{17}$. Uma forma de contornar este problema é a introdução de um grupo sulfato no frag- 
mento de sacarose destes compostos para aumentar a polaridade, como descrito no Esquema 3.

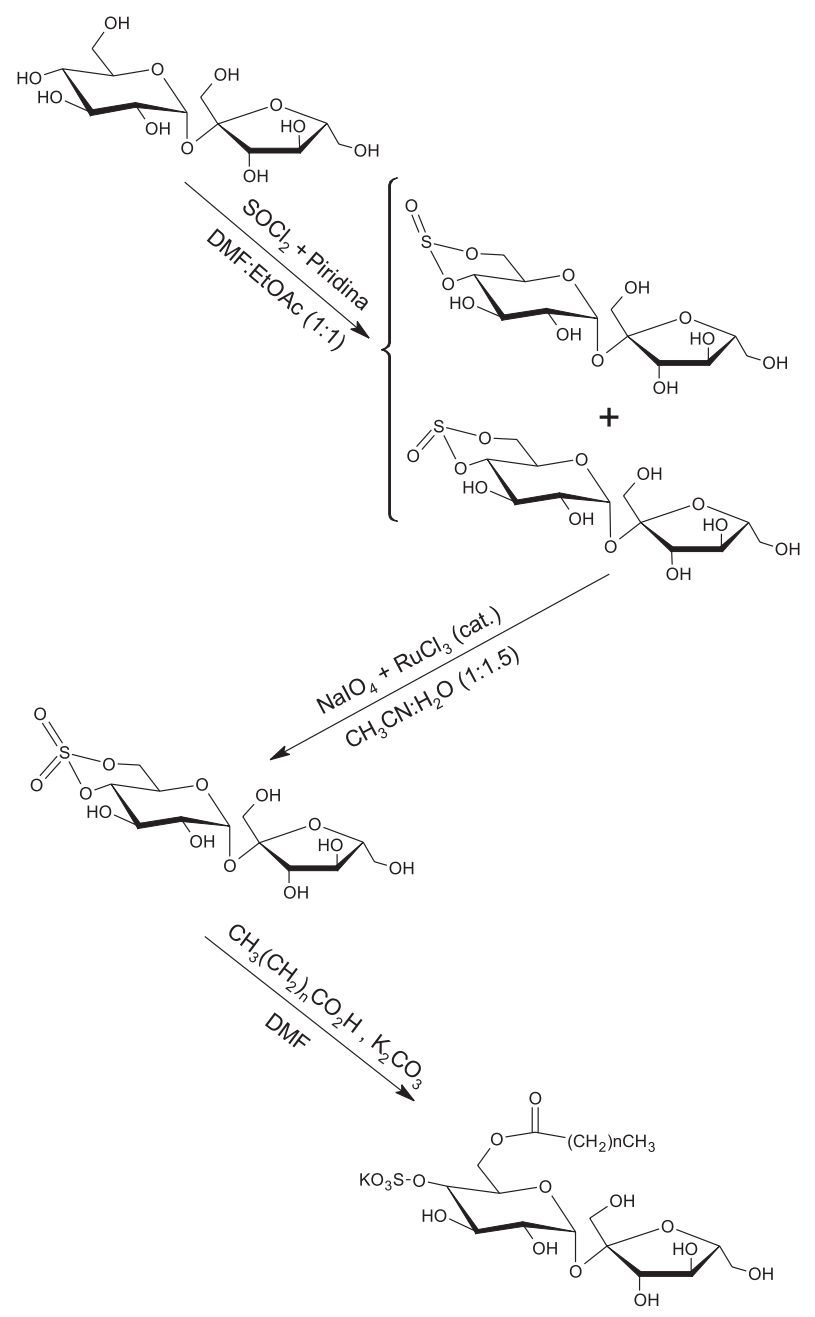

Esquema 3. Síntese de sucroéster sulfonado. (Outros isômeros são possíveis)

Sucroésteres geralmente apresentam uma baixa capacidade de formar microemulsões ${ }^{16}$, o que é possível somente na presença de co-surfactantes, como álcoois com $\mathrm{C} 2-\mathrm{C} 8$, podendo assim levar à solubilização até de $45 \%$ de água em óleo ${ }^{6}$, o que é muito desejável na indústria de cosméticos. Microemulsões de sucroésteres podem ser empregadas como "microrreatores" na produção de aromas para a indústria alimentícia ${ }^{18}$, com base na reação de Maillard, envolvendo furfural e cisteína.

Ao contrário dos mono, di e triésteres, os poliésteres de sacarose (mais de três hidroxilas esterificadas) são fracamente hidrolisados pela lipase intestinal ${ }^{19}$ e assim, muito pouco absorvidos pelo organismo $^{13}$. A olestra ${ }^{20}$ é um produto à base de poliésteres de sacarose obtidos a partir dos ácidos graxos de óleos vegetais, com grau de esterificação superior a seis e que apresenta propriedades físico-químicas semelhantes às dos glicerídios. Após a aprovação da olestra pelo FDA $^{21}$ em 1996, o seu uso vem sendo intensificado como substituto de óleos e gorduras na fabricação de produtos alimentícios rotulados como sem gordura "fat-free".

Devido à sua não digestibilidade e alta lipofilicidade, a olestra vem sendo também estudada como um agente de redução de colesterol pelo organismo ${ }^{22,23}$ e para o tratamento, por eliminação fecal, de contaminações crônicas por compostos lipofílicos persistentes ${ }^{24}$, como dibenzo-p-dioxinas, dibenzofuranos, difenilas policloradas (PCBs) e hexaclorobenzeno (HCB). Existem, entretanto, aspectos negativos no uso da olestra, pois sua ingestão reduz a absorção de vitaminas hidrofóbicas ${ }^{20}$ como A, D, E e K, o que pode ser compensado com a adição em excesso destas vitaminas aos alimentos processados com olestra. Outro inconveniente de sua ingestão, é a sua capacidade de poder provocar diarréia em alguns indivíduos.

Como exemplos de outras aplicações de sucroésteres na indústria alimentícia, pode-se citar o acetato-isobutirato de sacarose, um poliéster viscoso, conhecido comercialmente como SAIB ("sucrose acetate isobutirate"), empregado na correção de densidade em diversos tipos de bebidas ${ }^{25}$, e também, sucroésteres com HLB entre 2 e 6 , usados na prevenção da separação de fases em produtos compostos de misturas água/óleo como margarina, manteiga, chocolate, patê, entre outros, além de melhorar o volume e a textura de pães, bolos e similares ${ }^{5}$.

Com o uso de ésteres de sacarose é possível aumentar o tempo de prateleira de muitos vegetais. Produtos à base de sucroésteres, como o Semperfresh ${ }^{\circledR}$, proporcionam uma redução na oxidação de $\alpha$-farneseno em células hipodérmicas de maçã e pêra ${ }^{26}$, diminuindo assim o escurecimento destas frutas. No Brasil, já foram realizadas pesquisas, com resultados positivos na utilização de sucroésteres no amadurecimento de bananas ${ }^{27}$, tomates ${ }^{28}$ e pêssegos ${ }^{29}$.

Alguns ésteres de sacarose apresentam uma interessante propriedade controladora sobre bactérias mesofílicas e termofílicas formadoras de esporos, como Clostridium perfringens, em alimentos hermeticamente embalados ${ }^{30}$. Este controle é sinergicamente intensificado quando os sucroésteres são usados com outros compostos, como o ácido etilenodiaminotetraacético (EDTA) e éter fenilmetílico que, isoladamente, apresentam baixa atividade antimicrobiana.

A ação dos sucroésteres sobre bactérias não parece ocorrer pela solubilização da membrana celular, mas sim, devido a um estímulo enzimático autolítico denominado autólise. Em geral, a potência da atividade dos sucroésteres sobre microrganismos é regulada em função do ácido graxo empregado e do grau de substituição, sendo os monossucroésteres mais potentes que os poliésteres ${ }^{31}$.

Sucroderivados aromáticos são também encontrados em diversos vegetais. A partir da Phyllanthus niruri ${ }^{32}$, conhecida no Brasil como quebra-pedra, pode-se extrair a nirurisida (Figura 4), um poliéster de sacarose caracterizado como inibidor do HIV.

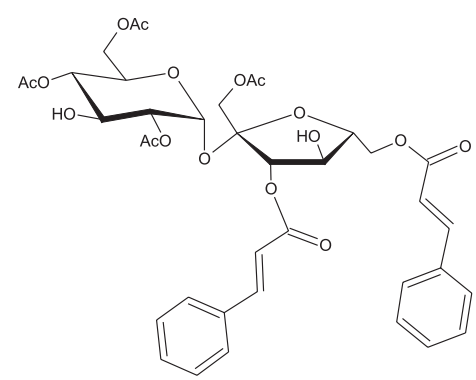

Figura 4. Estrutura da nirurisida (3',6'-O-di-trans-cinamato-2,3,4,6,1',4'O-hexacetilsacarose)

Espécies de Polygonum $\mathrm{sp}^{33,34}$ (erva-de-bicho) e Polygala $\mathrm{sp}^{35}$ (timutu) contêm sucroésteres com unidades dos ácidos ferúlico e cumárico em diversas posições na sacarose e são caracterizados como promissores agentes anti-carcinogênicos. Sucroésteres derivados do ácido gálico (ácido 3,4,5-tri-hidroxibenzóico) são agentes antioxidantes e podem ser empregados tanto em farmacologia ${ }^{36}$ como na indústria alimentícia ${ }^{37}$.

Em função da atividade biológica sobre alguns insetos e de serem encontrados em vegetais, alguns sucroésteres são classificados como pesticidas naturais ${ }^{38}$. Uma série de sucroésteres alifáticos com 
cadeia alquílica entre 7 a 12 carbonos extraídos de vegetais da família do tabaco (Nicotiniana $s p)^{39,40}$ foram eficientes no controle de pestes agrícolas, como a mosca branca (Bemisia argentifolii), que ataca diversas culturas agrícolas, como a batata doce e o tomate e está se tornando um sério problema para a agricultura do Brasil ${ }^{41}$. As vantagens deste tipo de pesticida são a biodegradabilidade e a atoxicidade para o homem. Neste sentido, pesquisas estão sendo dirigidas para um maior conhecimento de síntese em grande escala de diversos sucroésteres, bem como a caracterização de suas atividades biológicas ${ }^{42}$.

\section{Éteres de sacarose}

Assim como os ésteres, os éteres de sacarose são também substâncias anfifílicas que podem ser empregadas como surfactantes e emulsificantes $^{43}$. São mais resistentes a condições alcalinas moderadas, o que amplia suas aplicações. Os éteres alquílicos, vinílicos e alquil-benzílicos podem ser obtidos pela reação da sacarose com haletos orgânicos e os éteres hidroxialquílicos com epóxidos ${ }^{44}$ (Esquema 4).
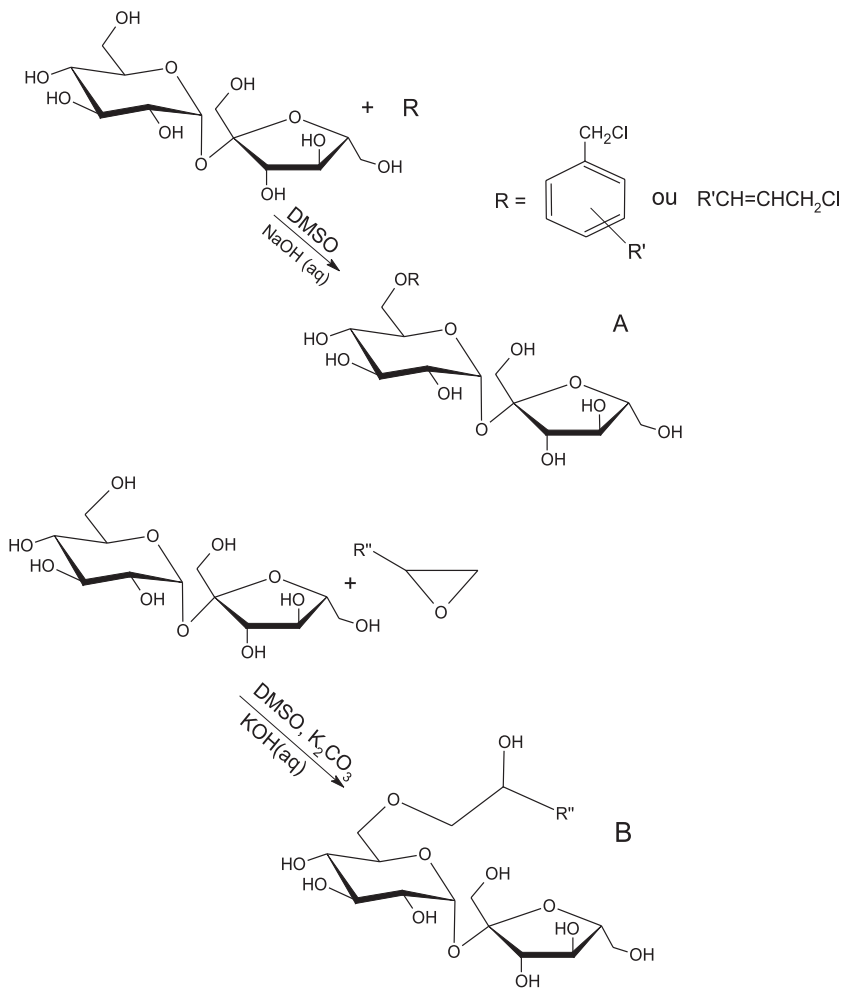

Esquema 4. Reações de eterificação da sacarose. (A) via cloretos orgânicos; (B) via epóxidos. (Outros isômeros são possíveis)

Sucroéteres com cadeias alquílicas curtas, solúveis em água, de baixa viscosidade e insípidos, como o hidroxipropilsacarose, obtido pela reação da sacarose com óxido de propileno ${ }^{45}$, podem ser utilizados agentes espessantes de alimentos ${ }^{46}$ ou como pré-polímeros na produção de poliuretanas semi-rígidas empregadas na construção de móveis, isolamento térmico de telhados etc. Para esta finalidade podese citar produtos como o Pluracol ${ }^{\circledR} 975$ da Basf, o Polystar ${ }^{\circledR}$ G-26 da SWD Urethane e o Vorano ${ }^{\circledR}$ da Dow Química.

\section{Adoçantes}

Adoçantes pouco calóricos também podem ser obtidos a partir da sacarose, como a isomaltose ${ }^{7}[\alpha-\mathrm{D}$-glicopiranosil- $(1 \rightarrow 6)-\mathrm{D}$ - glicopiranose], a isomaltulose $\mathrm{e}^{47}[\alpha-\mathrm{D}$-glicopiranosil- $(1 \rightarrow 6)-\mathrm{D}$ frutofuranose], e mais recentemente, a sucralose (4,1',6'-tricloro4,1',6'-trideoxigalactofrutose), aprovada para consumo pelo $\mathrm{FDA}^{48}$ em 1998 e com um poder adoçante médio de 600 vezes maior que o da sacarose ${ }^{49}$. Estudos têm indicado a sucralose como um composto anti-cariogênico e estável em temperaturas de cozimento de alimen$\operatorname{tos}^{47}$, o que amplia suas aplicações.

A sucralose é obtida pela cloração seletiva das hidroxilas $\mathrm{OH}-4$, OH-1' e OH-6' da sacarose, a partir do poliéster 2,3,6,3',4'-penta$O$-acetil sacarose (6-PAS). O 6-PAS pode ser obtido por desacetilação seletiva do octacetato de sacarose catalisada por enzimas proteolíticas $^{50}$ ou através de um engenhoso método via suporte polimérico $^{51}$. A síntese deste suporte polimérico (Esquema 5) é baseada na formação de um monômero de sacarose, o 2,3,3',4,4'-penta-

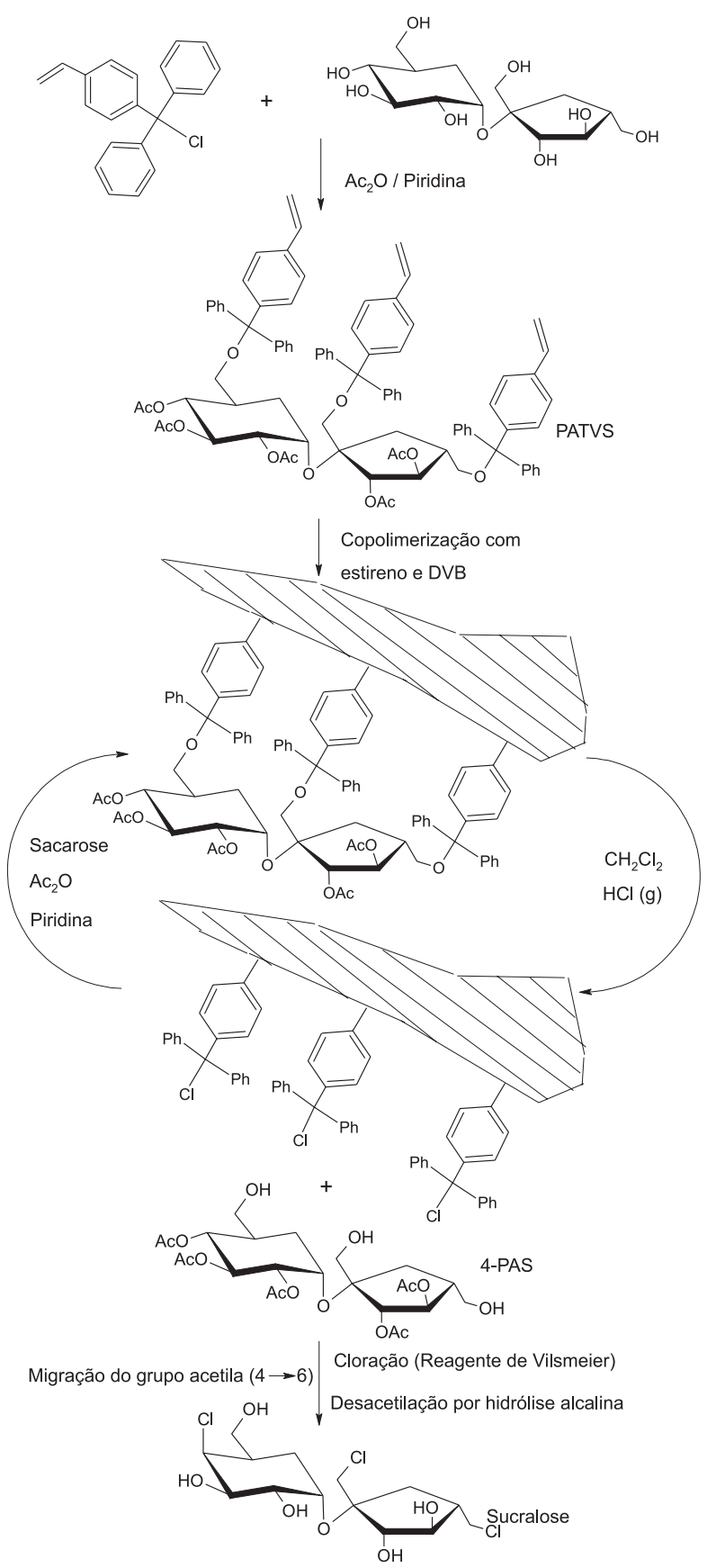

Esquema 5. Produção de sucralose por acetilação seletiva via suporte polimérico 
$O$-acetil-1',6,6'-tri- $O$-viniltritilsacarose (PATVS), pela reação da sacarose com o cloreto de 4-vinilfenil-di-fenilmetila (reagente seletivo para hidroxilas primárias), seguida de acetilação das hidroxilas secundárias com anidrido acético em piridina.

Com a copolimerização do PATVS com estireno e divinilbenzeno em tolueno e a posterior liberação da sacarose acetilada por clivagem ácida em solvente aprótico $\left(\mathrm{CH}_{2} \mathrm{Cl}_{2}-\mathrm{HCl}_{(\mathrm{g})}\right)$, pode-se obter o 2,3,4,3',4'-penta- $O$-acetilsacarose (4-PAS) e um suporte polimérico com uma "memória" para ligar-se às hidroxilas primárias de uma nova molécula de sacarose para acetilação de suas hidroxilas secundárias, seguido de novo processo de clivagem e assim continuamente. O 4-PAS é convertido em 6-PAS pela migração do grupo acetila de $4 \rightarrow 6$. A cloração das hidroxilas desbloqueadas $\mathrm{OH}-4, \mathrm{OH}-1$ ' e OH-6' é realizada com o reagente de Vilsmeier (Cloreto de Nclorometileno-N,N-dimetilamônio), formado in situ a partir da reação de dimetilformamida com cloreto de tionila ${ }^{52}$ na razão molar 7:1. Por meio de uma hidrólise alcalina, pode-se remover os grupos acetilas para, em fim, obter-se a sucralose.

Esta metodologia de regioproteção pode também ser explorada para outras finalidades que requeiram um número reduzido de hidroxilas disponíveis na sacarose.

\section{Polímeros de sacarose}

A produção de polímeros contendo a sacarose como parte da cadeia polimérica (sucrogéis) vem sendo pesquisada já há muitos $\operatorname{anos}^{53}$. A polimerização da sacarose é realizada de duas formas: (i) pela reação direta com compostos bifuncionalizados como diisocianatos $^{54}$ ou diácidos ${ }^{55}$ e (ii) por via radicalar envolvendo substituintes insaturados, sejam eles ésteres ${ }^{56,57}$ ou éteres ${ }^{9}$.

Sucrogéis podem ser aplicados em suturas cirúrgicas biodegradávei ${ }^{57}$ e como reguladores de fármacos ${ }^{58}$, pois, além da biocompatibilidade, apresentam uma capacidade de carregamento de drogas maior quando comparados com polietilmetacrilato, muito empregado para esta finalidade ${ }^{3}$. Outro exemplo de aplicação com ótimos resultados é o aproveitamento da bioespecificidade do poliacrilato de sacarose ligado com Cibacron Blue para a separação de albumina humana de outras proteínas ${ }^{59}$.

Para a formação de sucrogéis flexíveis via polimerização radicalar, idealmente apenas uma hidroxila da sacarose deve estar reativa para ser funcionalizada para a produção de monômeros. A obtenção de hepta- $O$-acetatos de sacarose pode ser alcançada com a ortoesterificação da sacarose com 1,1-dimetoxieteno ${ }^{60}$ (Esquema 6) com posterior acetilação das hidroxilas remanescentes. Com uma hidrólise levemente ácida, pode-se recuperar uma das duas hidroxilas não acetiladas para a incorporação de grupos químicos polimerizaveis.

Após o processo de polimerização, as hidroxilas acetiladas podem ser recuperadas por hidrólise alcalina.

Heptaésteres regioespecíficos de sacarose com o grupo hidroxila da posição 1 livre podem ser sintetizados através de sililação/ dessililação específica da sacarose com cloreto de $t$-butildifenilsilila ${ }^{61}$. Compostos como 2,3,4,6,1',3'6'-hepta- $O$-acetilsacarose, 2,3,4,3',4'penta- $O$-acetilsacarose e 2,3,6,3',4'-penta- $O$-acetilsacarose, podem ser obtidos por ação de enzimas proteolíticas específicas diretamente sobre o octa- $O$-acetato de sacarose ${ }^{50}$.

Uma das formas mais estudadas para a produção de sucrogéis é através da polimerização via radicalar de monômeros de sacarose funcionalizadas com metacrilato de glicidila. A reação da sacarose com metacrilato de glicidila (Esquema 7) pode ocorrer de duas formas $^{56}$ : (i) pela abertura do anel epóxido ou (ii) por transesterificação, sendo que esta última foi indicada como a via mais provável ${ }^{3}$.

Monômeros como monometacrilato e monoacrilato de açúcares são também produzidos por transesterificação em processos

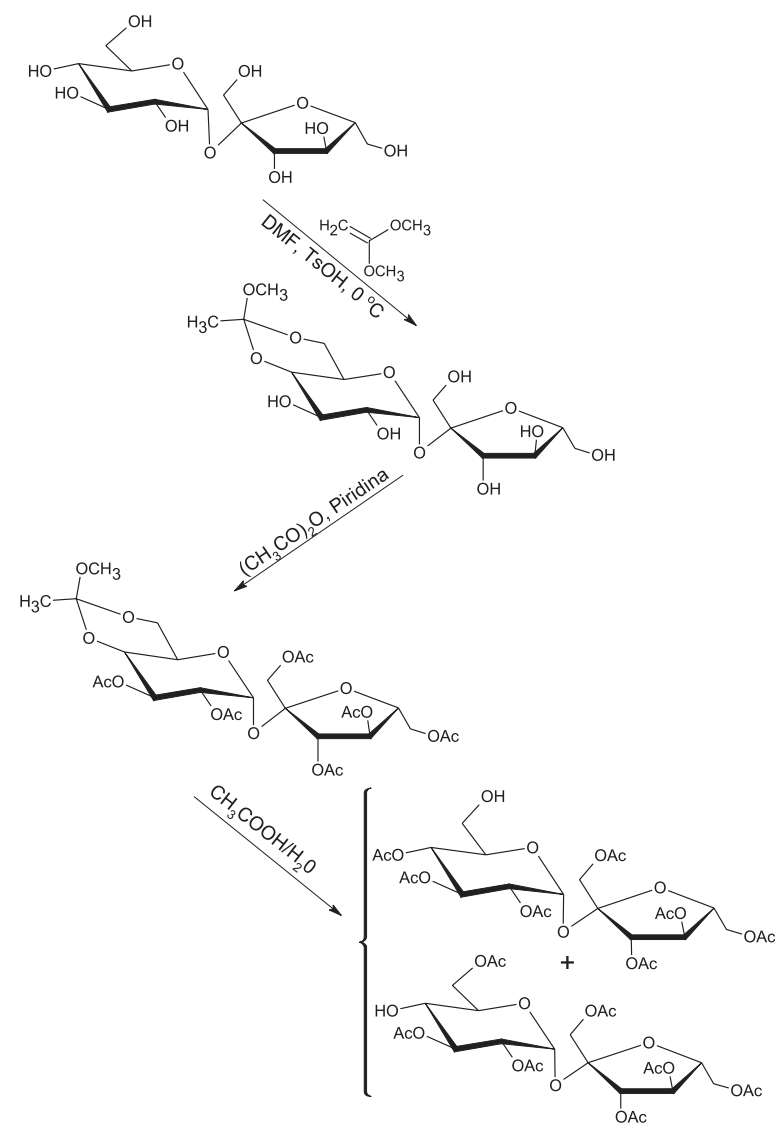

Esquema 6. Reações de regioproteção de hidroxilas da sacarose via formação de ortoésteres

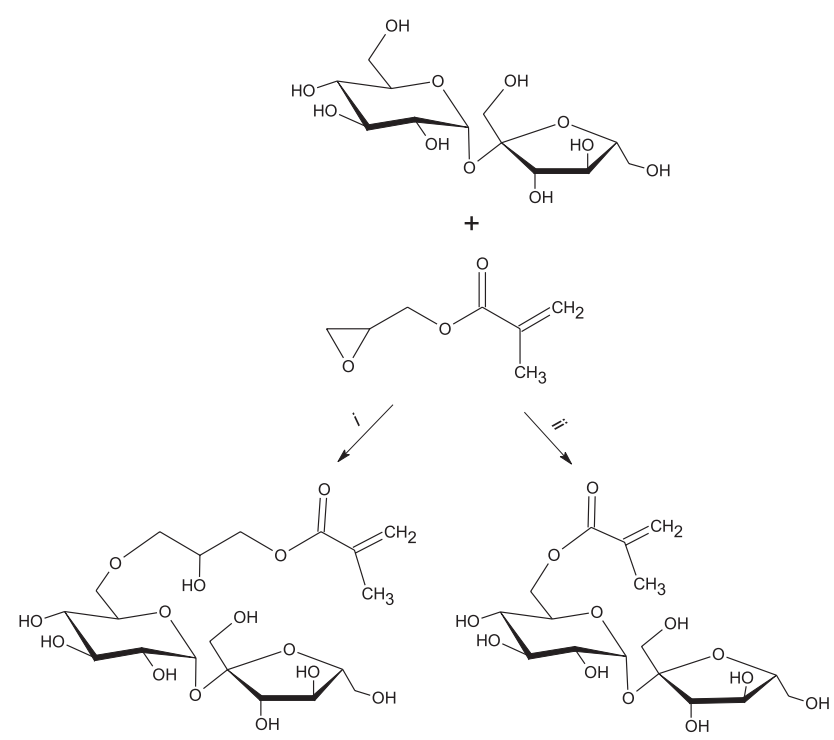

Esquema 7. Possíveis rotas de reação entre a sacarose e metacrilato de glicidila. (i) reação via abertura do anel epóxido; (ii) reação via transesterificação. (Outros isômeros são possíveis)

biocatalíticos ${ }^{62,63}$ sem, entretanto, a necessidade de proteção/ desproteção das hidroxilas da sacarose.

Derivados poliinsaturados de sacarose, como octa- $O$-alilsacarose e octa- $O$-crotilsacarose (Figura 5), são excelentes agentes 
reticuladores para polimetilmetacrilato ${ }^{64}$, chegando a elevar a temperatura de degradação térmica deste polímero de $284^{\circ} \mathrm{C}$ para $354^{\circ} \mathrm{C}$.

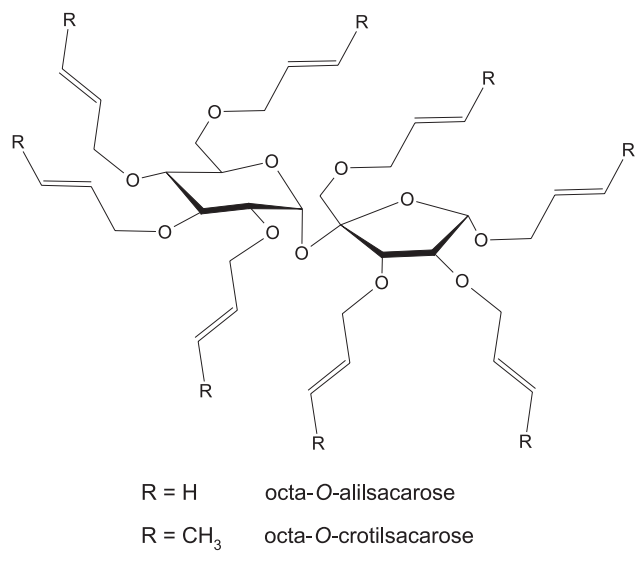

Figura 5. Exemplos de derivados poliinsaturados de sacarose

A introdução da sacarose em polímeros tradicionais (poliacrilatos, poliamidas, polietileno, entre outros) pode estender suas aplicações em função da incorporação de grupos polares, formação de copolímeros quirais, além de se tornarem parcialmente biodegradáveis ${ }^{63}$. Como exemplo, pode-se citar a copolimerização do estireno e metacrilato de sacarose produzindo copolímeros solúveis em água e com temperatura de transição vítrea (Tg) maior em relação ao poliestireno ${ }^{65}$.

Para a produção de poliuretanas de sacarose flexíveis é necessária a formação prévia de um diol, o que pode ser conseguido com a proteção de dois grupos hidroxilas vizinhos por meio da reação com 2-metoxipropeno ${ }^{54}$ para formação de um acetal cíclico (Esquema 8) e subseqüente acetilação das demais hidroxilas. Com uma hidrólise levemente ácida, recupera-se os grupos hidroxilas não acetilados que podem ser reagidos com diisocianatos. Após a polimerização, as hidroxilas acetiladas podem ser recuperadas por hidrólise alcalina.

Outra forma de se controlar o grau de reticulação de poliuretanas de sacarose é a substituição das duas hidroxilas primárias mais reativas (OH-6 e OH-6') por cloro, através da reação com trifenilfosfina e teracloreto de carbono em piridina (Esquema 9), produzindo assim o 6,6'-diclorosacarose. Desta forma, pode-se polimerizar a sacarose com diisocianatos ${ }^{54}$ envolvendo preferencialmente as hidroxilas das posições 2 e 1', as mais reativas dentre as remanescentes. Os melhores resultados foram conseguidos quando a razão molar entre 6,6'diclorosacarose e diisocianatos for próxima a 0,98 .

\section{CONSIDERAÇÕES FINAIS}

A sucroquímica é ainda um campo muito extenso a ser percorrido e a síntese de novos compostos a base de sacarose não é o único desafio a ser vencido, mas também o desenvolvimento de novas aplicações que despertem efetivo interesse econômico para os produtos já conhecidos.

A sacarose tem mostrado ser uma matéria-prima versátil, de crescente interesse tecnológico e muitos outros exemplos de seus derivados e aplicações podem ser listados. Entretanto, em pesquisa realizada junto a diversos bancos de dados, tendo como foco sínteses e aplicações de derivados de sacarose, observou-se que o número de teses, patentes ${ }^{66} \mathrm{e}$ artigos científicos produzidos pesquisadores brasileiros em sucroquímica não condiz com a importância do açúcar de cana na economia nacional. A reversão deste quadro pode ser um caminho para a geração de uma promissora atividade agro-industrial com novas perspectivas para os profissionais da área de química.
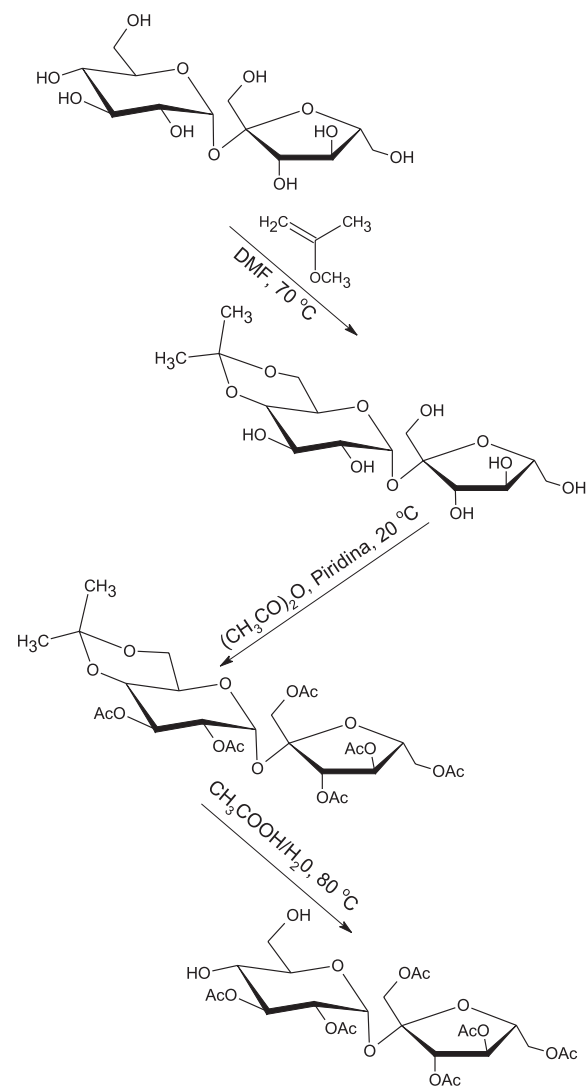

Esquema 8. Formação de pré-polímero de sacarose (2,3,1',3',4',6'-hexaO-acetilsacarose) via formação de um acetal cíclico. (Outros isômeros são possiveis)
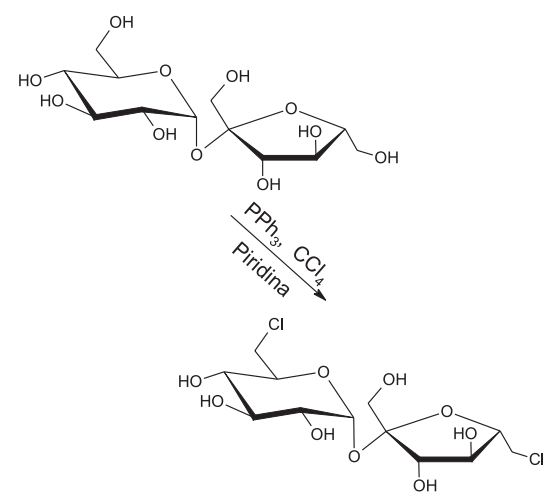

Esquema 9. Produção do pré-polímero 6,6'-diclorosacarose

\section{AGRADECIMENTOS}

O autor agradece aos Profs. E. Trabuco e D. W. Franco pelas discussões e à FAPESP, pelo financiamento do projeto em desenvolvimento dentro do Programa de Apoio à Jovens Pesquisadores.

\section{REFERÊNCIAS}

1. http://www.jornalcana.com.br/conteudo/DadoseEstatiscas.htm, acessada em Julho 2002.

2. Cruces, M. A.; Plou, F. J.; Ferrer, M.; Bernabé, M.; Ballestros, A.; J. Am. Oil Chem. Soc. 2001, 78, 541; Bouwstra, J. A.; van Hal, D. A.; Hofland, H. E.J.; Junginger, H. E.; Colloids Surf., A 1997, 123, 71; Nitschke M.; Pastore, G. M.; Quim. Nova 2002, 25, 772.

3. Ferreira, L.; Vidal, M. M.; Geraldes, C. F. G. C.; Gil, M. H.; Carbohydr. Res. 2000, 41, 15. 
4. Macindoe, W. M.; Williams, A.; Khan, R.; Carbohydr. Res. 1996, 283, 17. 5. Akoh, C. C.; J. Am. Oil Chem. Soc. 1992, 69, 9; Akoh, C. C.; Nwosu, C.; J. Am. Oil Chem. Soc. 1992, 69, 14.

6. Garti, N.; Aserin, A.; Fanun, M.; Colloids Surf., A 2000, 164, 27.

7 Ferreira, V. F.; Quim. Nova 1995, 18, 473.

8. Parker, K. J. Em Encyclopedia Of Chemical Technology; $3^{\text {rd }}$ ed., Grayson, M., ed.; John Wiley \& Sons: New York, 1981, vol. 21.

9. Sachinvala, N. D.; Winsor, D. L.; Menescasl, R. K.; Ganjian, I.; Nienczura, W. P.; Litt, M. H.; J. Polym. Sci., Part A: Polym. Chem. 1998, 36, 2397.

10. Thévenet, S.; Wernicke, A.; Belniak, S.; Descotes, G.; Bouchu, A.; Queneau, Y.; Carbohydr. Res. 1999, 318, 52.

11. Navia, J. L.; Roberts, R. A.; Wingard, R. E.; J. Carbohydr. Chem. 1995, $14,465$.

12. Garti, N.; Clement, V.; Leser, M.; Aserin, A.; Fanun, M.; J. Mol. Liq. 1999, $80,253$.

13. Akoh, C. C. Em Carbohydrate polyesters as fat substitutes; Akoh, C. C.; Swanson, B. G., eds.; Marcel Dekker, Inc: New York, 1994, cap. 2.

14. Muller, A.; Gagnaire, J.; Queneau, Y. ; Karaoglanian, M. ; Maitre, J. Bouchu, A. ; Colloids Surf., A 2002, 203, 55.

15. Rizzi, G. P.; Taylor, H. M.; J. Am. Oil Chem. Soc. 1978, 55, 398.

16. Jones, H. F.; US pat. 4,306,062 1981

17. Bazin, H. G.; Polat, T.; Linhardt, R. J.; Carbohydr. Res. 1998, 309, 189.

18. Fanum, M.; Leser, M.; Aserin, A.; Garti, N.; Colloids Surf., A 2001, 194, 175.

19. Williams, G. M.; Aardema, M. J.; Long, P. H.; Thompson, E. D.; Allgood, G. S.; Food Chem. Toxicol. 1996, 34, 941.

20. Thomson, A. B. R.; Hunt, R. H.; Zorich, N. L.; Aliment. Pharmacol. Ther. 1998. 12,1185

21. http://www.fda.gov/bbs/topics/NEWS/NEWS00524.html, acessada em Julho 2002.

22. Swanson, B. G.; Boutte, T. T.; Akoh, C. C. Em ref. 13, cap. 10

23. Ros, E.; Atherosclerosis 2000, 151, 357.

24. Moser, G. A.; McLachlan, M. S.; Chemosphere 1999, 39, 1513.

25. Reynalds, R. C.; Chappel, C. I.; Food Chem. Toxicol. 1988, 36, 81.

26. Bauchot, A. D.; John, P.; Soria, Y.; Racasens, I.; J. Am. Soc. Hort. Sci. 1995, $120,491$.

27. Tadini, C. C.; Silvério, L. G.; Resumos do $5^{\circ}$ Simpósio de Iniciação Científica da Universidade de São Paulo, São Paulo, Brasil, 1997.

28. Kluge, R. A.; Minami, K.; Sci. Agric. 1997, 54, 39.

29. Kluge, R. A.; Nachtigal, J. C.; Hoffmann, A.; Bilhalva, A. B.; Fachinello, J. C.; Rev. Agropecuar. Bras. 1998, 33, 109.

30. Sikes, A.; Ehioba, R.; Int. J. Food Microb. 1999, 46, 179.

31. Marshall, D. L.; Bullerman, L. B. Em ref. 13, cap. 8.

32. Cutrone, J. Q.; Huang, S.; Trimble, J.; Li, Hui.; Lin, P. F.; Alam, M.; Klhor, S. E.; Kadow, K. F.; J. Nat. Prod. 1996, 59, 196.

33. Takasaki, M.; Kuroki, S.; Kozuka, M.; Konoshima, T. J.; J. Nat. Prod. 2001, 64, 1305.

34. Sum, X.; Zimmermann, M. L.; Campagne, J. M.; Sneden, A. T.; J. Nat. Prod. 2000, 63, 1094.
35. Zhang, D.; Myiase, T.; Kuroyanagi, M.; Umehara, K.; Noguchi, H.; Phytochemistry 1998, 47, 45.

36. Uhrig, R. K.; Picard, M. A.; Beyreuther, K.; Wiessler, M.; Carbohydr. Res. 2000, 325, 72

37. Potier, P.; Maccario, V.; Giudicelli, M. B.; Queneau, Y.; Dangles, O.; Tetrahedron Lett. 1999, 40, 3387.

38. Chortik, O. T.; Kays, S. J.; Teng, Q.; J. Agric. Food Chem. 1997, 45, 270.

39. Chortik, O. T.; Pomonis, J. G.; Johnson, A. W.; J. Agric. Food Chem. 1996, $44,1551$.

40. Liu, T. X.; Stansly, P. A.; Chortyk, O. T.; J. Econ. Entomol. 1996, 89, 1233.

41. O Estado de São Paulo, Suplemento Agrícola, 05/12/2001.

42. Oscarson, S.; Ritzén, H.; Carbohydr. Res. 1996, 284, 271.

43. Gagnaire, J.; Tomaran, G.; Descotes, G.; Bouchu, A.; Queneau, Y.; Tetrahedron Lett. 1999, 40, 2757.

44. Gaertner, V. R.; J. Am. Oil Chem. Soc. 1961, 38, 410

45. Hinz, W.; Dexheimer, E. M.; US pat. 6,380,367 2002.

46. Yadav, M. P.; Bemiller, J. N.; Wu, Y.; J. Carbohydr. Chem. 1994, 13, 991.

47. Khan, R. Em Sucrose. Properties and applications; Mathlouthi, M.; Reiser, P., eds.; Blackie Academic \& Professional: Glasgow, 1995, cap. 11.

48. http://www.cfsan.fda.gov/ lrd/tpsucral.html, acessada em Julho 2002.

49. Mann, S. W.; Yuschak, M. M.; Amyes, S. J. G.; Aughton, P.; Finn, J. P.; Food Chem. Toxicol. 2000, 38, S91.

50. Palmer, D. C.; Terradas, F.; Tetrahedron Lett. 1994, 35, 1673.

51. Macindoe, W. M.; Jenner, M.; Williams, A.; Carbohydr. Res. 1996, 289, 151

52. Krause, W.; Paust, J.; Dobler, W.; Jaedicke, H.; US pat. 5,344,995 1994

53. Booth, R. E.; US pat. 3,369,014 1968.

54. Jhurry, D.; Deffieux, A.; Eur. Polym. J. 1997, 33, 1577.

55. Robyt, J.; Mukerjea, R.; US pat 6,281,351 1996.

56. Chen, J.; Park, K.; Carbohydr. Res. 2000, 41, 259.

57. Patil, N. S.; Li, Y.; Rethwisch, D. G.; Dordick, J. S.; J. Polym. Sci., Part A: Polym. Chem. 1997, 35, 2221.

58. Patil, N. S.; Dordik, J. S.; Rethwisch, D. G.; Biomaterials 1996, 17, 2343.

59. Zamora, M.; Strumia, M.; Bertorello, H.; Polym. Bull. 1996, 37, 483.

60. Bouchra, M.; Gelas, J.; Carbohydr. Res. 1998, 305, 17.

61. Barros, M. T.; Maycock, C. D.; Thomassigny, C.; Carbohydr. Res. 2000, $328,419$.

62. Potier, P.; Bouchu, A.; Descotes, G.; Queneau, Y.; Tetrahedron Lett. 2000, 41,3597

63. Martin, B. D.; Ampofo, S. A.; Linhardt, R. J.; Dordick, J. S.; Macromolecules 1992, 25, 7081 .

64. Sachinvala, N. D.; Ju, R. F.; Litt, M. H.; Niemczura, W. P.; J. Polym. Sci., Part A: Polym. Chem. 1995, 33, 15.

65. Fanton, E.; Fayet, C.; Gelas, J.; Deffieux, A.; Fontanille, M.; Jhurry, D.; Carbohydr. Res. 1993, 240, 143.

66. http://www.inpi.gov.br/pesq_patentes/patentes.htm, acessada em Janeiro 2003. 